\title{
Geometrie Was ist ein Punkt?
}

$\mathrm{E}$ in Punkt hat keine Teile und eine Linie bzw. Gerade ist durch Punkte gegeben, so jedenfalls der antike Mathematiker Euklid. Und auch heute heißt es, ein Punkt sei ausdehnungslos. Widerspricht das nicht jeder auf sinnlicher Anschauung basierenden Erfahrung? Etwas, das ausdehnungslos ist, kann nicht teilbar sein, oder doch? Ich frage mich, wieso dann ein physikalisch-empirischer Raumpunkt dann doch teilbar ist und ob er endlich oder unendlich teilbar ist? Der Widerspruch ist oft angesprochen worden, schon im 5. Jahrhundert v. Chr. hat Parmenides' Schüler Zenon verschiedene Paradoxa aufgestellt, das berühmteste ist das von Achill und der Schildkröte. Zenon argumentiert, dass das Schnellste (Achill) das Langsamste (die Schildkröte) nie einholen würde. Denn immer müsse der Verfolger (Achill) erst dort ankommen, wo die Schildkröte vorher schon weggegangen sei. Es müßten also eine unendliche Anzahl von Teilstrecken durchlaufen werden - Achill holt also die Schildkröte niemals ein, weil der Vorsprung zwar zunehmend kleiner wird, aber dennoch niemals aufhören kann. Zenon zeigt also, dass diese unendliche Teilbarkeit zu einem paradoxen Ergebnis führt.

Wenn der Punkt als mathematisch-ideales Gebilde - also unteilbar und ausdehnungslos - angesehen wird, wie verbindet sich das mit der physikalisch-empirischen Erfahrung, dass Achill und die Schildkröte real eine Raum- und Zeitstrecke von Punkten durchlaufen und somit Achill die Schildkröte ganz sicher mit einem Schritt überholen wird? 